\title{
Editorial: Structure and Mechanical Properties of Titanium Alloys and Titanium Matrix Composites (TMCs)
}

\author{
Lechun Xie ${ }^{1,2 *}$, Liqiang Wang ${ }^{3}$, Lai-Chang Zhang ${ }^{4}$ and Weijie Lu $^{3}$ \\ ${ }^{1}$ Hubei Key Laboratory of Advanced Technology for Automotive Components, Wuhan University of Technology, Wuhan, \\ China, ${ }^{2}$ Hubei Collaborative Innovation Center for Automotive Components Technology, Wuhan, China, ${ }^{3}$ State Key \\ Laboratory of Metal Matrix Composites, School of Materials Science and Engineering, Shanghai Jiao Tong University, \\ Shanghai, China, ${ }^{4}$ School of Engineering, Edith Cowan University, Perth, WA, Australia
}

Keywords: titanium alloy, titanium matrix composite (TMC), microstructure, mechanical properties, manufacturing, application, heat treatment

\section{Editorial on the Research Topic}

\author{
Structure and Mechanical Properties of Titanium Alloys and Titanium Matrix \\ Composites (TMCs)
}

Titanium alloys and titanium matrix composites (TMCs) have wide application prospects in aerospace, automobile, biomedicine, and other industries because of their combination of excellent properties such as high specific strength, good ductility, excellent fatigue properties, and corrosion resistance. With industrial and biomedical development, the improvement in mechanical properties of titanium alloys and TMCs is required. As such, the novel design, manufacturing,

OPEN ACCESS

Edited and reviewed by: John L. Provis,

University of Sheffield, United Kingdom

*Correspondence: Lechun Xie

lechunxie@yahoo.com

Specialty section: This article was submitted to

Structural Materials,

a section of the journal

Frontiers in Materials

Received: 06 April 2020

Accepted: 15 April 2020

Published: 30 April 2020

Citation:

Xie L, Wang L, Zhang L-C and Lu W (2020) Editorial: Structure and

Mechanical Properties of Titanium

Alloys and Titanium Matrix

Composites (TMCs).

Front. Mater. 7:118.

doi: 10.3389/fmats.2020.00118 mechanical modification, and other aspects of materials science, are of vital importance to titanium alloys and TMCs. In the contents of this topic, many endeavors are made regarding the modification of microstructure and mechanical properties of titanium alloys and TMCs via various methods.

In the aspect of TMCs, Wen et al. investigated the microhardness of micron-level $\mathrm{TiC}$ and $\mathrm{TiB}$ reinforcements in in-situ synthesized (TiC+TiB)/Ti-6Al-4V via nanoindentation, and they verified that the nanoindentation method was a very useful method to characterize the microhardness of reinforcements in TMCs. Li J. et al. studied the effect of heat treatment on the creep properties of in-situ synthesized ( $\left.\mathrm{TiB}+\mathrm{La}_{2} \mathrm{O}_{3}\right) / \mathrm{Ti}$. The widmanstätten and lamellar $\alpha$ structure formed after the new TRIPLEX heat treatment, which enhanced the creep strain and the elongation. The fracture mechanism was attributed to the breakage of $\mathrm{TiB}$ and the creep fracture mechanism was due to the load transfer of $\mathrm{TiB}$ and the interfacial debonding.

In terms of titanium alloys after laser treatment and selective laser melting (SLM), Zhang et al. investigated the microstructure and mechanical properties of $\mathrm{Ti}-35 \mathrm{Nb}-2 \mathrm{Ta}-3 \mathrm{Zr}$ by laser quenching. The dislocations and $\alpha^{\prime}$ martensite transformation were generated during laser quenching, and a coarse grain structure was also obtained. After laser quenching, the superelasticity and microhardness were increased, but the toughness was decreased. Li M. et al. studied the dimensional deviation of SLMed Ti-6Al-4V blade. The microstructure observations illustrated that the acicular $\alpha^{\prime}$ martensite formed in prior $\beta$ grains, and the smaller the grain size, the larger the dimensional deviation. The directions of dimensional deviation at the leading and trailing edges were opposite to those in the middle, which was caused by the thermal stresses.

In the aspect of titanium alloys after heat treatment, Gai et al. investigated the hot deformation behavior of a novel near- $\beta$ titanium alloy Ti-5.5Mo-6V-7Cr-4Al-2Sn-1Fe in the $(\alpha+\beta)$ phase region. During the thermal deformation, the $\alpha$ phase content decreased with an increase in the strain rate, and the size of $\alpha$ decreased with increasing temperature. Furthermore, the $\alpha$ phase precipitated 
after short-term aging preferentially nucleated within the grains. Cheng et al. characterized the hot deformation behavior of Ti-25.5Al-13.5Nb-2.8Mo-1.8Fe through the processing map, which showed a stable region under a temperature range of $950-1,100^{\circ} \mathrm{C}$ with the strain rate range of $0.001-1 \mathrm{~s}^{-1}$. However, the alloy sustained a deformation instability phenomenon while the strain rate exceeded $1 \mathrm{~s}^{-1}$. Ma et al. studied the effect of annealing temperature on microstructure and properties of metastable $\beta$ Ti-35Nb-2Ta-3Zr for biomedical applications. The sample annealed at $923 \mathrm{~K}$ presented the best elasticity and the highest recovery strain $(\sim 66.87 \%)$. The corrosion rate of the sample annealed at $923 \mathrm{~K}$ was the lowest, which was attributed to its minimum content of $\alpha$ " phase.

The contributions of the above work were summarized as following: the characterization methods for structure and mechanical properties of titanium alloys and TMCs (Cheng et al.; Li J. et al.; Wen et al.); the manufacturing methods for titanium alloys by SLM (Li M. et al.); the modification of the mechanical properties, e.g., surface treatment, and heat treatment (Cheng et al.; Gai et al.; Li J. et al.; Zhang et al.); the simulation of the stress distribution of titanium alloys (Li M. et al.); the application of titanium alloys in biomedicine (Ma et al.). This Research Topic focused on the recent development of titanium alloys and TMCs (e.g. design, manufacturing, characterization, structure, mechanical properties), and all the results presented would promote the development of titanium alloys and TMCs.

\section{AUTHOR CONTRIBUTIONS}

LX and LW wrote the editorial. L-CZ and WL revised and modified the editorial.

Conflict of Interest: The authors declare that the research was conducted in the absence of any commercial or financial relationships that could be construed as a potential conflict of interest.

Copyright (c) 2020 Xie, Wang, Zhang and Lu. This is an open-access article distributed under the terms of the Creative Commons Attribution License (CC BY). The use, distribution or reproduction in other forums is permitted, provided the original author(s) and the copyright owner(s) are credited and that the original publication in this journal is cited, in accordance with accepted academic practice. No use, distribution or reproduction is permitted which does not comply with these terms. 